\title{
A SCIENTIFIC STUDY OF PERCEPTIONS AND PATTERNS OF CONTRACEPTIVE (MANAE-HAMAL TADABEER) USAGE AMONG WOMEN OF REPRODUCTIVE AGE IN WESTERN MAHARASHTRA
}

\author{
Naeela Ansari* and Farha Rizwan \\ Department of Tahaffuzi-Wa-Samaji Tib \\ Z.V.M. Unani Medical College, Pune, Maharashtra
}

\section{Review Paper}

Received: 25.05.2021

Revised: 07.06.2021

Accepted: 15.06.2021

\begin{abstract}
Background:Although all parts of the world have seen a huge increase in contraceptive usage, at least 200 million women still currently lack access to modern contraceptives(Manae-hamaltadabeer). Today about 53.4\% eligible couples are still unprotected against conception. Successful fertility control leads to many social and economic advantages for women from educational attainment, personal autonomy to relationship stability and satisfaction.

Material and Method:A cross-sectional study was carried out from Jan 2018 to Jan 2019 to analyse the awareness, perceptions and various patterns of contraceptives usage among 1000 women of reproductive age in western Maharashtra.

Observation and Result:Data were collected from 1000 women participants. 266 (26.6\%) belong to the age group of 25-29 years of age and Mean age of women was 32.78 years with $S D+7.58$ yrs. $100 \%$ Awareness was observed whilemajority of 622 (62.2\%) use contraceptive methods. About 226 (22.6\%) preferred Condom. There was a significant association between age $\left(\mathrm{X}^{2}=49.37, \mathrm{p}=0.0001\right)$, educational status $\left(\mathrm{X}^{2}=439.46, \mathrm{p}=0.0001\right)$,Socio Economic Status $\left(\mathrm{X}^{2}=72.1311, \mathrm{P}=0.000\right)$,family Type $\left(\mathrm{X}^{2}=14.44, \mathrm{p}=0.001\right)$ and Parity $\left(\mathrm{X}^{2}=55.79, \mathrm{p}=0.00001\right)$ with the knowledge scores. There was significant association between preference of contraceptive methods scores and the age $\left(X^{2}=104.32, p=0.000\right)$, Education $\left(X^{2}=99.97, p=0.000\right)$, SES $\left(\mathrm{X}^{2}=77.953, \mathrm{p}=0.000\right)$ and parity $\left(\mathrm{X}^{2}=65.50, \mathrm{p}=0.000\right)$.

Conclusion:Despite 100\% awareness and favourable attitude, significant number of reproductive age women did not use contraceptive methods due to various reasons. This study shows the association between socio-demographic variables and family planning acceptance ratio.
\end{abstract}

No. of Pages: 7

References: 15

Keywords: Contraceptive method, Perception, Patterns of contraceptive usage.

\section{INTRODUCTION}

The current World population is 7.4 Billion. India with a population of 1210 million in the year 2011 is the second most populous country in the world, however India is the first country to launch a nationwide family planning programme in the year 1952. According to UN projection India's population will reach 1.53 billion by the year 2050, this will make India the most populous country in the World (www.Worldometers; 2018). According to National family health survey-4 (2015-16)(www.rchiips.org $>$ NFHS $>$ India) about $12.9 \%$ of currently married women in India have an unmet need for family planning. Only $40 \%$ eligible couples in

*Corresponding author: drnaeelak@gmail.com 
the reproductive age group of 15 to 44 years were effectively protected against conception by contraceptive methods in the year 2011 (K. Park 2015) .Unintended pregnancy are associated with increased risk of unsafe abortion, maternal, foetal \& child morbidity and mortality .It is evident that use of effective contraceptive method would potentially prevent $90 \%$ of abortion ,20\% of pregnancy related morbidity and $32 \%$ of maternal death worldwide (Http/Science.Jrank.Org). Keeping all these facts in view, this study was carried out to assess the knowledge level, perceptions and patterns of contraceptive usage among reproductive age women of western Maharashtra.

\section{MATERIALAND METHOD}

A cross-sectional study was carried out from Jan 2018 to Jan 2019 to analyse the awareness, perceptions and various patterns of contraceptives usage among 1000 women of reproductive age in western Maharashtra. Written consent was taken from participants. A pretested and semi structured questionnaire was used to assess socio-demographic profile, knowledge index, source of knowledge, perception, Family type, parity and current contraceptive choices, collected data was statistically analysed in SPSS version 22. Chi Square test was used to assess the level of significance between two variables.

\section{Ethical considerations}

The study was approved by the Medical Ethics Committee of the M.C.E. Society, Azam Campus, Pune. Due care was taken to ensure that all those who agreed to participate in the study did so voluntarily. Written informed consent was obtained from the respondents prior to data collection.

\section{Observation and Result}

Among the 1000 females in the study group,266 (26.6\%) belong to the age group of 25-29 years of age and Mean age of women was 32.78 years with SD \pm 7.58 yrs. Majority of 596 (59.6\%) had UG/PG Education and 1\% women were illiterate. Most of the women $37.6 \%$ belonged to Social Class III and least (8.2\%) belonged to Social class V. Among the participants, 848 (84.8\%) belong to nuclear family. About 87 (64\%) got married at the age of $19-25$ years and 59 (43.4\%) had 2-3 years of married life. Majority of women (73.1\%) had two children and least (1.7\%) had four children. About 76 (55.9\%) had one living child. Among the participants 134 (98.5\%) got the information through health personnel (Table 1).

\section{Knowledge on contraceptive methods}

Majority of 649 (64.9\%) had moderate knowledge, 148 (14.8\%) had high knowledge and 203 (20.3\%) had low knowledge on contraceptive methods (Table2).

\section{Attitude or perception on contraceptive methods}

Majority of 895 (89.5\%) had favourable attitude and 105
(10.5\%) had unfavourable attitude towards contraceptive methods (Figure 1).

\section{Practice of contraceptive methods}

Majority of 622 (62.2\%) use contraceptive methods. About 226 (22.6\%) used Condom and minimum 49 (4.9\%) of the females used other methods of contraceptives such as calendar method and natural method. (Table3). Majority of 603 (60.3\%) were using contraceptive method in the past and 397 (39.7\%) were not using any contraceptive method. The reason for discontinuation was desire for pregnancy 99(9.9\%), side effect 50 (5\%) and method failure 42(4.2\%).

\section{Preferences of contraceptive Method among Females}

Only two Participant women were under age of 20 Yrs in our study and they both preferred Cu-T. As observed majority (49\%) of women in the age group of 45-49years preferred terminal methods of contraception. Condom was preferred $(49.7 \%)$ by the women of $25-29$ years. CuT (28.1\%) was preferred by the age group of 35-39 years women and Pills (21.4\%) in the age group of $30-34$ years. $39.1 \%$ \& $42 \%$ women of higher socio-economic status preferred Condom as a temporary method of contraception whereas $35.4 \%$ \& $64.5 \%$ women who belonged to social class IV and V preferred Female Sterilization. Condom was preferred in 42.2\% women having PG/UG level of education while Female Sterilization was most preferred method of contraception in $100 \%$ women who were illiterate. Condom was most preferred method in women of both Nuclear and Joint Family. Condom was most preferred method in women with 0,1,2 parity, while women having 3 children preferred Female Sterilization (Table 3).

\section{Association between knowledge with the variables}

There was a significant association between age $\left(X^{2}=49.37\right.$, $\mathrm{p}=0.0001)$, educational status $\left(\mathrm{X}^{2}=439.46, \mathrm{p}=0.0001\right)$, Socio Economic Status $\left(\mathrm{X}^{2}=72.1311, \mathrm{P}=0.000\right)$, family Type $\left(\mathrm{X}^{2}\right.$ $=14.44, \mathrm{p}=0.001)$ and Parity $\left(\mathrm{X}^{2}=55.79, \mathrm{p}=0.00001\right)$ with the knowledge scores (Table 3).

\section{Association between attitude with the variables}

There was significant association between attitude scores regarding contraceptive methods and the age, Education, SES and parity except family type inferring that the attitude on contraceptive methods is independent of type of family.

\section{Association between preference of contraceptive methods with the variables \\ There was significant association between preference of contraceptive methods scores and the age $\left(X^{2}=104.32\right.$, $\mathrm{p}=0.000)$, Education $\left(\mathrm{X}^{2}=99.97, \mathrm{p}=0.000\right)$, $\operatorname{SES}\left(\mathrm{X}^{2}=77.953\right.$, $\mathrm{p}=0.000)$ and parity $\left(\mathrm{X}^{2}=65.50, \mathrm{p}=0.000\right)$ except family type $\left(X^{2}=5.031, p=0.284\right)$ inferring that the choice of contraceptive methods is independent of type of family.}




\section{DISCUSSION}

1. Knowledge, attitude, practices and preferences on contraceptive methods among the female population In the present study, Majority of participant $64.9 \%$ had medium knowledge index. 20.3\% women had low Knowledge and $14.8 \%$ had High knowledge about contraception. Similarly, Sonam Zangmu in her study reported that among 136 women, Majority of participant $67.60 \%$ had moderate knowledge, $17.60 \%$ had low knowledge and $14.70 \%$ had high knowledge of contraceptive methods. (Sonam Zangmu 2013). In this study, a majority of 895 (89.5\%) had favourable attitude and 105 (10.5\%) had unfavourable attitude towards contraceptive methods. Similar observation (approval- 87.5\% \& Disapproval $12.5 \%$ ) has been found in the study of S. Zangmu. (S. Zangmu. 2013). In our study, 62.2\% users, Condom was most preferred method (22.6\%) of contraception followed by Female sterilization (12.3\%) and CuT (12.2\%). Non user contributed $37.8 \%$ of total study population. Similar study done by Prachi in Maharashtra reported that Contraception usage was higher in the urban women (62.5\%) and less in the rural women (37.5\%) (Prachi et al 2014), while NFHS-3 shows 64\% contraceptive usage among reproductive age women in urban area. The U.P based study conducted by Anjali Singh illustrated that among six cities of U.P,24.3\% women adopted Condom as a contraceptive method in Gorakhpur \&25.9\% in Allahabad, which are close to the results of this study (Anjali Singh; 2016). A similar pattern was also found in the study conducted in Uganda in 2016, where the most commonly mentioned method used was Condom (34.5\%). (Henry N. Subuga; 2016).

2. Association between knowledge scores on contraceptive methods with the variables: In the present study, there was a significant association between age $\left(\mathrm{X}^{2}\right.$ =49.37, $\mathrm{p}=0.0001)$, educational status $\left(\mathrm{X}^{2}=439.46\right.$, $\mathrm{p}=0.0001)$, Socio Economic Status $\left(\mathrm{X}^{2}=72.1311, \mathrm{P}=0.000\right)$, family Type $\left(X^{2}=14.44, p=0.001\right)$ and $\operatorname{Parity}\left(X^{2}=55.79\right.$, $\mathrm{p}=0.00001$ ) with the knowledge scores, whereas according to a study by Rao on knowledge and use of contraception among Racha Koyas of Andhra Pradesh in 2005 (Rao; 2005) literacy did not make any influence in the increase of knowledge. The findings are supported by a study conducted by Julie on 'A comparative study to determine the knowledge, attitude and practice of married women regarding family welfare in selected urban and rural areas of Udupi district', Karnataka in 2000 where education was found to be significantly associated with knowledge scores $\left(\mathrm{X}^{2}=6.37\right.$, $\mathrm{p}<0.05)$ in rural areas and $\left(\mathrm{X}^{2}=4.98, \mathrm{p}<0.05\right)$ in urban areas (Julie; 2000). Similarly, a study conducted in Qatari women by Arbab reported that low knowledge was found in women who belonged to low Socio-Economic Status (Arbab; 2011). On a contrary, in a Pakistan based study (Salma Hameed;2019) Parity has no effect on knowledge of contraceptive method.

\section{Association between attitude scores on contraceptive} methods with the variables:In the present study, there was significant association between attitude scores with the variables except family type, which contradict the study conducted by Julie on 'a comparative study to determine the knowledge, attitude and practice of married women regarding family welfare in selected urban and rural areas of Udupi district', Karnataka in 2000 where there was no association between attitude scores with the variables (Julie; 2000).

\section{Association between preference of contraceptive methods with the variables:}

Female Sterilization (46.8\%) was the most preferred method in women having Low awareness. Condom was the most preferred method (38.6\% \% 37\%) among women with both medium and High Knowledge index. Women with medium level of awareness preferred CuT \& pills in equal ratio (20\% \&19.4\%) after Condom. Those who approve the use of contraception, their most preferred method was condom (36.5\%) while those who disapprove the use of contraception, preferred Other methods (58.8\%) of contraception. Terminal method of contraception were preferred as age progress. As observed 49\% in the age group of $45-49 y e a r s$. Condom was preferred $(49.7 \%)$ in the age group of 25-29 years followed by CuT (28.1\%) and Other methods (10.5\%) in the age group of 35-39 years and Pills (21.4\%) in the age group of 30-34 years. On the contrary, study by Prateek reported that Copper-T was the most common contraceptive measure used by 24 (41.3\%) study participants (Prateek; 2012). It is observed that women of higher socio-economic status preferred Condom (39.1\%) as a temporary method of contraception, whereas 35.4\% \& 64.5\% women from social class IV and V respectively preferred Terminal methods (Female Sterilization). These differences were highly significant. In a similar study of Prateek and Jahan Uruj, Low Socioeconomic group was observed with low contraceptive usage, whereas High usage was reported in high income group (Prateek; 2012) (Jahan Uruj et al; 2017). Temporary methods utilization showed an increasing trend with increase in education level among women. Chi square test showed highly significant relationship between educational level of HSC \& above graduation and condom usage, Intermediate \& below HSC with Female sterilization. Similarly, Manipur study also stated the usage of Pills \& CuT being higher among women with secondary or University 
degree. While Female sterilization was more frequent among the primary educated and illiterate women (Donati et al; 2003). Condom was most preferred method in women belonging to both Nuclear and Joint Family i.e. 188(35.9\%) and 38 (38.4\%) respectively. Condom was most preferred method in women with 0,1,2 and 4 parity, while women having 3 children preferred Female Sterilization. Similar results were reported by Jahan Uruj in her study conducted in Uttar Pradesh (Jahan Uruj et al; 2017)

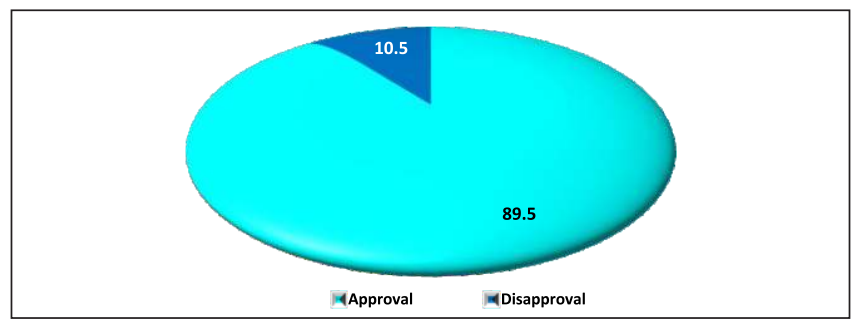

Figure 1: Distribution of women according to their Perception of Contraception.

Table 1: Frequency and percentage distribution of sample characteristics.

\begin{tabular}{|c|c|c|c|}
\hline \multicolumn{2}{|c|}{ Sociodemographic Parameters } & $\mathbf{n}$ & $\%$ \\
\hline \multirow{7}{*}{ Age } & $<20$ & 6 & 0.6 \\
\hline & $20-24$ & 117 & 11.7 \\
\hline & $25-29$ & 266 & 26.6 \\
\hline & $30-34$ & 228 & 22.8 \\
\hline & 35-39 & 166 & 16.6 \\
\hline & $40-44$ & 122 & 12.2 \\
\hline & $45-49$ & 95 & 9.5 \\
\hline \multirow{6}{*}{ Education } & Illiterate & 10 & 1.0 \\
\hline & Mid School & 60 & 6.0 \\
\hline & HSC & 258 & 25.8 \\
\hline & Intermediate & 30 & 3.0 \\
\hline & PG/UG & 596 & 59.6 \\
\hline & Prof/Honours & 46 & 4.6 \\
\hline \multirow{5}{*}{ SES } & I & 101 & 10.1 \\
\hline & II & 341 & 34.1 \\
\hline & III & 376 & 37.6 \\
\hline & IV & 100 & 10.0 \\
\hline & $\mathrm{V}$ & 82 & 8.2 \\
\hline \multirow{2}{*}{ Family Type } & Nuclear & 848 & 84.8 \\
\hline & Joint & 152 & 15.2 \\
\hline \multirow{4}{*}{ Age at Marriage } & $<20$ & 121 & 12.1 \\
\hline & $20-24$ & 581 & 58.1 \\
\hline & $25-29$ & 281 & 28.1 \\
\hline & $30-34$ & 11 & 1.1 \\
\hline \multirow{3}{*}{ Parity } & $<1$ & 128 & 12.8 \\
\hline & $1-2$ & 731 & 73.1 \\
\hline & $3-4$ & 14 & 14.1 \\
\hline \multirow{5}{*}{ Source of knowledge } & Private Doctors & 511 & 51.1 \\
\hline & Government Hospital & 177 & 17.7 \\
\hline & Friends & 44 & 4.4 \\
\hline & Media & 320 & 32 \\
\hline & Relatives & 266 & 26.6 \\
\hline
\end{tabular}


Table 2: Chi Square values computed between the knowledge scores on contraceptive methods and the variables.

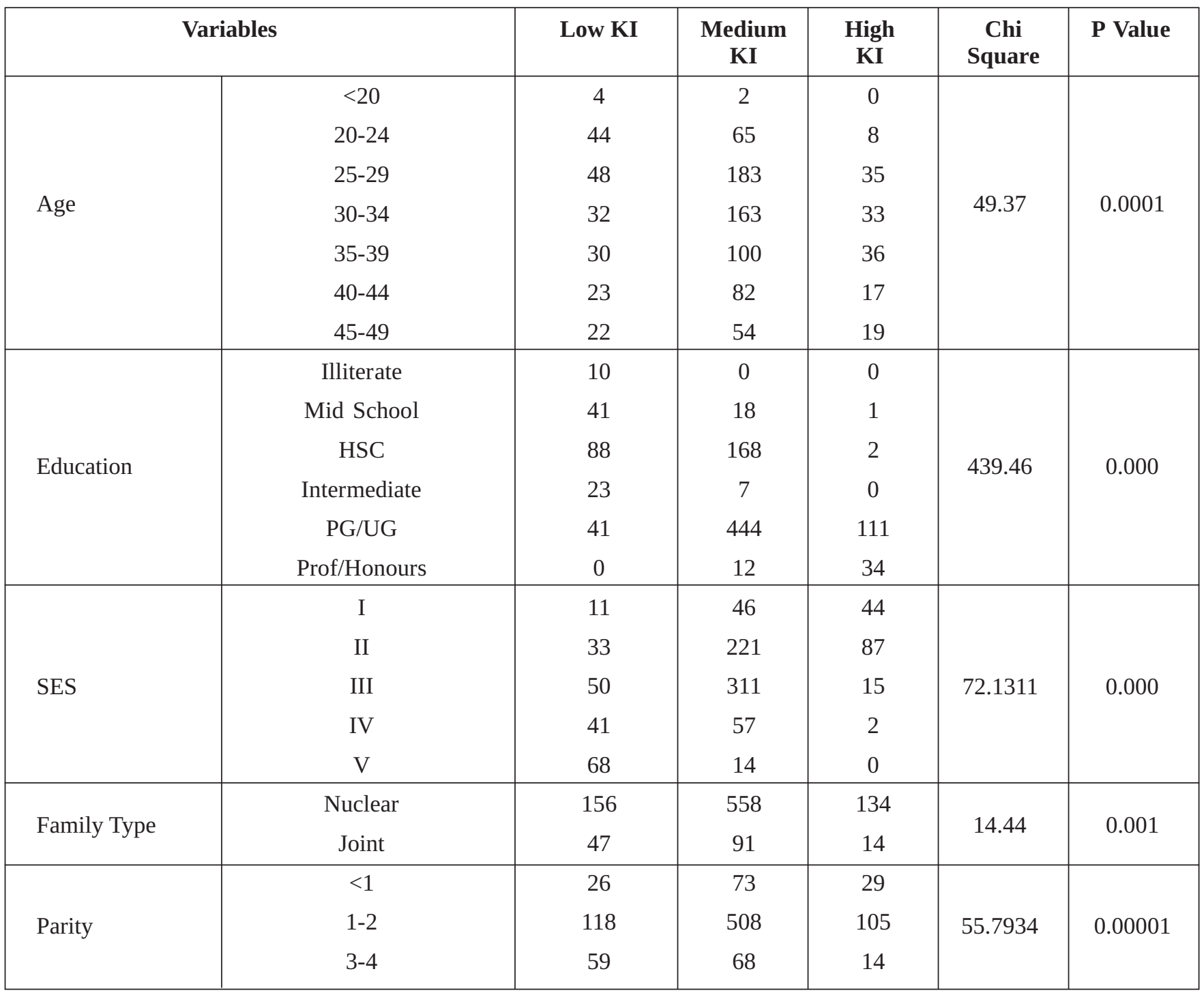

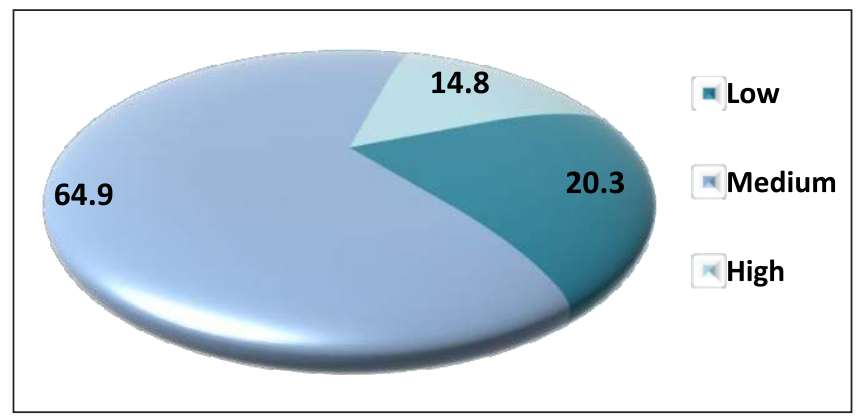

Figure 2: Distribution of knowledge Index on contraceptive methods. 
Table 3: Chi Square values computed between the choice of contraceptive methods and the variables.

\begin{tabular}{|c|c|c|c|c|c|c|c|c|}
\hline & Variables & Low KI & Medium & High & Chi & P Value & P Value & P Value \\
\hline & $<20$ & 0 & 0 & 2 & 0 & 0 & & \\
\hline & $20-24$ & 31 & 7 & 8 & 2 & 0 & & \\
\hline & $25-29$ & 84 & 29 & 28 & 13 & 15 & & \\
\hline Age & $30-34$ & 42 & 33 & 35 & 32 & 12 & 104.32. & 0.000 \\
\hline & $35-39$ & 30 & 10 & 32 & 30 & 12 & & \\
\hline & $40-44$ & 30 & 16 & 11 & 21 & 6 & & \\
\hline & $45-49$ & 9 & 7 & 6 & 25 & 4 & & \\
\hline & ILLLITERATE & 0 & 0 & 0 & 2 & 0 & & \\
\hline & MID SCHOOL & 6 & 2 & 6 & 18 & 2 & & \\
\hline Education & HSC & 41 & 19 & 38 & 40 & 4 & 99971 & O \\
\hline & INTERMEDIATE & 2 & 0 & 4 & 12 & 0 & & \\
\hline & PG/UG & 168 & 75 & 69 & 46 & 40 & & \\
\hline & PROF/HONOURS & 9 & 6 & 5 & 5 & 3 & & \\
\hline & I & 27 & 11 & 14 & 11 & 6 & & \\
\hline & II & 94 & 45 & 38 & 27 & 20 & & \\
\hline SES & III & 84 & 42 & 50 & 42 & 15 & 77.953 & 0.000 \\
\hline & IV & 12 & 4 & 18 & 23 & 8 & & \\
\hline & V & 9 & 0 & 2 & 20 & 0 & & \\
\hline & Nuclear & 188 & 88 & 109 & 98 & 40 & & \\
\hline 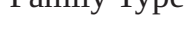 & Joint & 38 & 14 & 13 & 25 & 9 & 0.001 & 0.204 \\
\hline & $<1$ & 32 & 9 & 0 & 0 & 0 & & \\
\hline Parity & $1-2$ & 172 & 91 & 108 & 92 & 45 & 65.5002 & 0.000 \\
\hline & $3-4$ & 20 & 2 & 14 & 31 & 4 & & \\
\hline
\end{tabular}

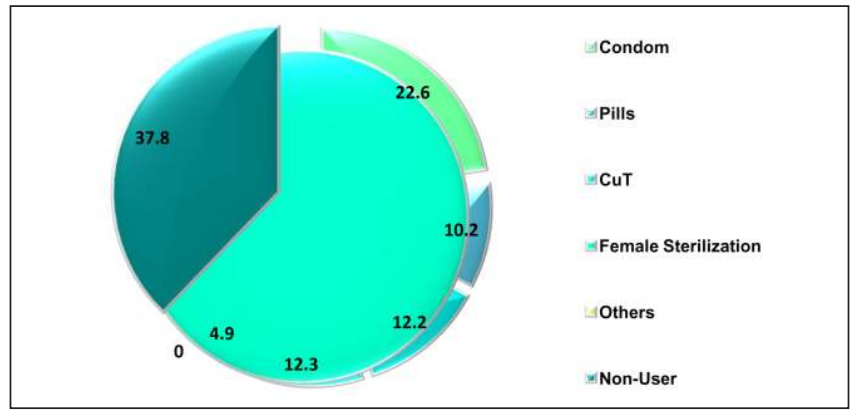

Figure 3: Distribution of Non user and patterns of Contraceptive choices among Users. 


\section{CONCLUSION}

The present study aimed to assess the knowledge, attitude, practice and preferences on contraceptive methods among the reproductive age females of Western Maharashtra. The following conclusions were made based on the findings of the study:

$>$ The findings show that awareness regarding contraception was universal, but contraceptive use was suboptimal. Despite having 100\% awareness, only $62.2 \%$ women used at least one contraceptive method, while $37.8 \%$ women were observed to be non-user.

$>$ Most of the females had moderate knowledge and favourable attitude on contraceptive methods.

$>$ Contraceptive method was practiced by the females, among which condom were mostly used and preferred by them.

$>$ There was a significant association between age, educational status, socio-economic status, family type and parity with the knowledge scores. This emphasizes the importance of education in improving the knowledge of the females on contraceptive methods.

$>$ There was significant association between attitude and the other variables except Family type.

$>$ Age, Education, socioeconomic status and parity played critical role in contraceptive methods utilization while Family type (Nuclear/Joint) had no significant effect on Contraception adoption.

\section{ACKNOWLEDGEMENTS}

I express my sincere thanks to my mentor Dr Farha Rizwan; Associate Professor and Dr Jalees Ahmad; Principal Z.V.M. Unani Medical College, Pune for their guidance. I express my deep sense of gratitude whole heartedly to Dr Nasreen Shaikh for her help in data analysis.

\section{REFERENCES}

1. A.A. Arbab, A. Benerand M. Abdul Malik; Prevalence, awareness and determinants of contraceptive use in Qatari women; Eastern Mediterranean Health Journal; Vol. 17 No. 12011.

2. Anjali Singh, K. K. Singh and Prashant Verma; Knowledge, attitude and practice GAP in family planning usage: an analysis of selected cities of Uttar Pradesh; Contraception and Reproductive Medicine (2016) 1:20
3. Donati S, Sharma N, Medda $\mathbf{M}$ et al. Family planning knowledge attitude and practice survey in Manipur state J ObstetGynecol India. 2003;53:485-90.

4. Henry N. Subuga, Juliet N. Sekandi, Hassard Sempeera and Fredrick E. Makumbi, Contraceptive Use, Knowledge, Attitude, Perceptions and Sexual Behaviour Among Female University Students in Uganda: A Cross -Sectional Survey, BMC Women's Health, 2016 16:6.

5. Http/Science.Jrank.Org/Pages/1761/Contraception-An Ancient Interest. (Cited 4/4/2018)

6. Jahan U, Verma K, Gupta S, Gupta R, Mahour S, Kirti N, et al. Awareness, attitude and practice of family planning methods in a tertiary care hospital, Uttar Pradesh, India. Int J Reprod Contracept ObstetGynecol 2017; 6:500-6.

7. Julie; A Comparative Study to Determine the Knowledge, Attitude and Practice of Married Women Regarding Family Welfare in Selected Urban and Rural Areas of Udupi District. M.Sc. Nursing Thesis submitted to Manipal college of nursing, MAHE. 2001

8. K. Park, Park's Textbook of Preventive \&Social Medicine 23rdEdition, M/S BanarsidasBhanot Publishers 2015, pp: 479-519.

9. P. Durga Rao and M. Sudhakar Babu; Knowledge and Use of Contraception Among RachaKoyas of Andhra Pradesh; Anthropologist, 7(2): 115-119(2005)

10. Prachi S Koranne, Aparna R Wahane; An Analysis of Awareness and Utilization of Contraceptives Amongst Married Woman Attending A Tertiary Care Hospital in Maharashtra, India; National Journal of Community Medicine | Volume 5 | Issue 4 | Oct-Dec 2014;373-377

11. Prateek S.S, Saurabh R.S., Contraceptive Practices Adopted by Women Attending an Urban Health Centre, African Health Sciences 2012; (4): 416-421

12. www. rchiips.org $>$ NFHS $>$ India accessed on 15/05/2019

13. Salma Hameed, Noman Ul Haq, Naheed Haque, Aqeel Nasim, Sohail Riaz, Maria Tahir, Muhammad Saood, Riffat Yasmin and Muhammad Samsoor Zarak; Knowledge, Attitude and Practices (KAP) Regarding Family Planning Services among Married Women of Quetta Pakistan. International Journal of Research and Reports inGynecology. 2(1): 1-12, 2019.

14. Sonam Zangmu Sherpa, Melita Sheilini, Asha Nayak; Knowledge, Attitude and Preferences of Contraceptive Methods in Udupi District, Karnataka; J. Family and Reproductive Health, Vol.7, No.3, Sept.2013.

15. www.Worldometers.Info/Worldpopulation Cited On 27/06/2018. 